\title{
Incidence of Nephropathy in HIV Infected Patients Receiving Highly Active Antiretroviral Therapy at Newlands Clinic: A Retrospective Study
}

\author{
T. Shamu1, M. Wellington', M. Pascoe1, L. Gwanzura², C. E. Ndhlovu² \\ ${ }^{1}$ Newlands Clinic, Harare, Zimbabwe \\ ${ }^{2}$ College of Health Sciences, University of Zimbabwe, Harare, Zimbabwe \\ Email: tinei.shamu@gmail.com
}

Received 19 April 2015; accepted 6 June 2015; published 11 June 2015

Copyright (C) 2015 by authors and Scientific Research Publishing Inc.

This work is licensed under the Creative Commons Attribution International License (CC BY). http://creativecommons.org/licenses/by/4.0/

c) (†) Open Access

\section{Abstract}

Introduction: HIV infected patients on antiretroviral therapy (ART) are at risk of developing nephropathy and therefore require monitoring of renal function. Some medications used in the management of HIV, opportunistic infections (OIs) and other co-morbidities are nephrotoxic and may further compromise renal function, underlining the importance of regular monitoring of renal function. This study was designed to determine the incidence of nephropathy in HIV infected patients on antiretroviral therapy (ART) at Newlands Clinic and to determine the associated risk factors. Methodology: A retrospective cohort study was conducted involving $1986 \mathrm{HIV}-1$ infected participants who were commenced on ART between January 2007 and December 2013 at Newlands Clinic. The majority of participants were female $(1340(67.5 \%))$. All participants were aged 18 or older at ART commencement. Participants with pre-existing nephropathy at baseline were excluded. Nephropathy was defined as two consecutive calculated creatinine clearances $(\mathrm{CrCl})$ less than $60 \mathrm{ml} / \mathrm{min}$ by the Cockcroft-Gault equation, or two consecutive urine dipsticks positive for protein ( $\geq 30 \mathrm{~g} / \mathrm{L}$ albumin). Data collected during routine patient visits were exported from the clinic's database and analysed for incidence of nephropathy and risk factors. Results: During the follow-up period, 93 of the 1986 participants $(4.7 \%)$ developed nephropathy. The estimated incidence rate (IR) of nephropathy was $1.45 / 100$ person years (CI: $1.17-1.78)$. In the multivariate analysis, statistically significant risk factors were baseline age $>45$ (HR 2.30, CI: $1.50-3.55$ ), diabetes mellitus (HR 4.12, CI: 1.75 - 9.69), pulmonary tuberculosis (HR 2.00, CI: 1.28 - 3.12), and HIV wasting syndrome (HR 2.72, CI: 1.30 - 5.68). Conclusion: The incidence of nephropathy was low in this cohort. The traditional risk factors for renal disease; older age and diabetes mellitus were significant, as well as HIV wasting syndrome and pulmonary tuberculosis. HIV care should be complimented with proper diabetic care and patients that develop pulmonary tuberculosis, HIV 
wasting syndrome or are initiated on ART above 45 years require regular monitoring for early detection of nephropathy.

\title{
Keywords
}

\author{
Zimbabwe, Nephropathy, ART Management, HIV, Creatinine Clearance
}

\section{Introduction}

Among HIV infected patients, nephropathy can be caused by HIV related and non-HIV related pathologies. Non-HIV related pathologies include hypertension, diabetes mellitus, atherosclerosis, toxicities of medicines, as well as other infections [1]. HIV-associated nephropathy (HIVAN) is the most common form of kidney disease found in the HIV-infected population [2]. It is a unique clinical and pathological entity thought to be secondary to direct HIV infection of renal cells [3]-[5].

HIVAN is more common in patients with African ancestry due to a genetic variation in the APOL1 gene on Chromosome 22 and is common in African chromosomes but absent from European chromosomes [6]-[8]. Glomerular and renal epithelial cells are the primary targets of HIV pathogenesis in the kidney. The essential pathologic process is dysregulation of the epithelial cell cycle with increased proliferation, apoptosis, cellular dedifferentiation, and altered cellular polarity [5] [9]. Gerntholtz et al. found HIVAN in 27\% of patients who had kidney biopsies done, and HIV immune complex kidney disease (HIVICK) in 21\% in a South African study [6].

In the United States of America, progression to End Stage Renal Disease (ESRD) was found to be six-fold higher in HIV infected veterans of African descent compared to other races [10]. In a cohort study performed in Baltimore, Maryland assessing incidence of CKD, glomerular filtration rate slope and progression to ESRD in 4259 participants (78.2\% African American), Lucas et al. found a CKD incidence of 11.2 per 1000 person-years. African American participants developed ESRD markedly faster than did white participants (HR, 17.7 [95\% CI, 2.5 - 127.0]) [11].

The widespread use of antiretroviral therapy (ART) has influenced the epidemiology of HIV related kidney disease (HIVAN) by reducing mortality rates of ESRD among HIV infected individuals as well as incidence of HIVAN even though the protective effect of ART was only partial [6] [12]-[14]. Late initiation of ART has been suggested as a possible cause of poor renal outcomes [7] [14]. Antiretroviral drugs such as tenofovir (TDF), which is part of the preferred first line regimen in Zimbabwe, have been shown to cause renal toxicity, particularly proximal renal tubular dysfunction (PRTD) [15]-[18]. TDF together with indinavir (IDV), are the antiretroviral agents mostly associated with kidney toxicity since both are excreted via the kidney [19]-[26].

Cumulative exposure to antiretroviral medications TDF, IDV, Atazanavir (ATV) and Lopinavir/r (LPV/r) has been shown to increase risk of CKD in a cohort study by Mocroft et al. which included 6843 HIV infected individuals [22]. Participants in this study were from 103 centres in Europe, Israel and Argentina. The majority of them were male (75.1\%) and Caucasian (85.5\%). Incidence of CKD in this study was 1.05 per 100 person-years follow-up.

Other comorbidities such as cardiovascular disease, hypertension and diabetes mellitus have been known to be associated with chronic kidney disease (CKD) and ESRD among HIV negative individuals, and this association is also true among HIV infected individuals [27]-[30]. A combined cross sectional and one year follow up study where HIV infected participants were screened for proteinuria or significant impairment of glomerular function and then 424 of those that were negative in the screening were followed up for one year was performed in Tokyo, Japan. In this study Ando et al. found that HIV infected diabetic patients were four times likely to have tubular damage than HIV infected non-diabetics. They underscored the importance of urine protein screening for early detection of renal tubular damage [31].

Aging has been identified as one of the risk factors for CKD among HIV infected patients with increases in prevalence being more pronounced among HIV infected veterans than non-infected [32] [33].

Medications implicated in eliciting kidney injury include prophylactic cotrimoxazole when administered concomitantly with TDF in patients with low CD4+ cell counts [34]. Nonsteroidal anti-inflammatory drugs 
(NSAIDs) and rifampicin may cause acute interstitial nephritis in patients. NSAIDs may also promote prerenalazotaemia in patients with true or effective intravascular volume depletion [21]. Antimicrobials used to treat opportunistic infections such as amphotericin B, acyclovir, foscarnet and pentamidine may also be nephrotoxic. Early detection and discontinuation of these antimicrobials can help avert kidney failure [23].

Angiotensin Converting Enzyme Inhibitors (ACEIs) and Angiotensin Receptor Blockers (ARBs), two groups of anti-hypertensive drugs, have been shown to have a protective effect on the kidney [35]. Use of these nephroprotective drugs as the preferred first line treatment for hypertension has been advocated for in the Recommendations of the HIV Medicine Association of the Infectious Diseases Society of America [36]. There has been overwhelming evidence demonstrating better renal outcomes in patients treated with ACEIs and ARBs compared to the other classes of antihypertensive drugs, and the protective effect has also been shown in HIV infected individuals [35] [37]. It should be noted though that ACEIs are contraindicated in patients with known or suspected renovascular disease unless blood pressure control cannot be attained by other classes of antihypertensive medication. They should also be used with caution in patients with peripheral vascular disease and severe generalised atherosclerosis [38].

The American Primary Care Guidelines for the Management of Persons Infected with HIV note that kidney function may be abnormal in up to $30 \%$ of HIV infected patients. In that respect, they recommend that a baseline urinalysis and calculated creatinine clearance $(\mathrm{CrCl})$, especially in black HIV-infected patients and those with advanced disease or comorbid conditions. They also recommend that urinalysis and $\mathrm{CrCl}$ should be performed prior to initiating drugs such as TDF or IDV that have the potential for nephrotoxicity [39]. Furthermore, Gupta et al. recommend biannual monitoring of renal function in patients receiving IDV or TDF [36].

There is currently no information on the incidence of nephropathy in patients receiving ART in Zimbabwe. The current Zimbabwean National ART Guidelines do not give concise instructions on the recommended frequency of laboratory monitoring of renal function in patients receiving ART or in those awaiting ART initiation.

The majority of published studies related to kidney disease have focused mainly on prevalence and not incidence probably because data on ART experiences in resource limited settings where HIV is more prevalent is only becoming available now as the scale up of ART continues to improve ART coverage. There is, therefore an unknown proportion of HIV infected patients receiving ART in Zimbabwe who are at risk of developing nephropathy due to the various etiologies of nephropathy among HIV infected individuals. These patients are also at risk of drug toxicities secondary to impaired renal function and may progress to end-stage renal failure. The inability to detect nephropathy in the early stages results in prolonged exposure to the offending medication and lack of appropriate dose adjustment. ART in resource limited settings is often given in fixed drug formulations, making dose adjustment in patients with nephropathy extremely difficult if not impossible.

\section{Methods}

An observational retrospective cohort study to determine the incidence of, and factors associated with nephropathy in HIV infected patients on ART at Newlands Clinic.

Data for 1986 participants who were HIV infected, aged above 18 years and commenced ART between 1 January 2007 and 31 December 2013 were analysed. Participants with pre-existing nephropathy at baseline were excluded. Nephropathy was defined as two consecutive $\mathrm{CrCl}$ measurements less than $60 \mathrm{ml} / \mathrm{min}$ or two consecutive urine dipsticks that were positive for protein.

Secondary data were extracted using SQL Server 2012 from the clinic’s electronic medical record, ePOC ${ }^{\odot}$. The database is used by the clinic staff as a point of care electronic medical record in the clinical care of patients, it is password protected and patient confidentiality for the study was ensured by the use of anonymised codes. The following data were extracted from the database: $\mathrm{CrCl}$ determined by the Cockcroft-Gault equation, urine protein measured with Roche Combur ${ }^{9}$ and Combur ${ }^{10}$ urine dipsticks, demographic data, diagnoses and medications. The SQL output was exported to Microsoft Excel, and then imported into STATA 12.0 where cleaning and analysis was done.

Participants who developed nephropathy were followed up from the date of the first $\mathrm{CrCl}$ measurement or urine dipstick until the date with the first of two consecutive abnormal measurements. Follow up of participants who did not develop nephropathy was censored at the date of the last laboratory measurement. The criterion defining a nephropathy with the earliest date was used i.e. either $\mathrm{CrCl}$ or proteinuria.

The statistical analyses used were the two sample test of proportions, Wilcoxon Rank Sum test to compare the medians of continuous variables and the Cox regression model for multivariate analysis. Data were regarded as 
statistically significant when the $P$-value was $<0.05$ (two-tailed test).

As secondary data was used in this study, no major risks were posed to the participants. There were also no direct benefits to the participants but the results will lead to improved care of HIV infected individuals.

The study was approved by the Newlands Clinic Research team, the Joint Parirenyatwa Hospital and College of Health Sciences Research Ethics Committee (JREC Ref:230/13), the Biomedical Research and Training Institute (BRTI) Institutional Review Board (IRB) and the Medical Research Council of Zimbabwe (MRCZ/B/ 589).

Newlands Clinic is part of the International epidemiologic Databases to Evaluate AIDS-Southern African Region (IeDEA-SA). This work was supported by Grant number 2U2RTW007367 from the Fogarty International Centre, National Institutes of Health (NIH, USA) through the International Clinical, Operational and Health Services and Training Award (ICOHRTA). The content is solely the responsibility of the authors and does not necessarily represent the official views of the National Institutes of Health. Laboratory tests and consultations done on patients were paid for by Swiss AIDS Care International (SACI).

\section{Results}

A total of 1986 participants were included in the study whose total follow up time was 6411 person years. Out of the 1986 participants, ninety three $(4.7 \%, \mathrm{n}=93 / 1986)$ participants developed nephropathy. Of these ninety three, sixty one $(65.6 \%, n=61 / 93)$ were classified as defined by two consecutive urine screen tests positive for proteinuria, while 32 (34.4\%) were classified as defined by two consecutive $\mathrm{CrCl}$ results $<60 \mathrm{ml} / \mathrm{min}$ calculated using the Cockcroft-Gault equation. The classification was mutually exclusive.

The estimated incidence rate of nephropathy in the study population was 1.45/100 person years (CI: 1.17 1.78). The Kaplan-Meier survival estimate for development of nephropathy over time in this cohort is shown in Figure 1. When disaggregated by sex, the incidence was higher among males (2.06/100 person years (CI: 1.47 $2.80)$ ) than females $(1.19 / 100$ person years (CI: 0.89 - 1.55)), but male sex was not a statistically significant independent risk factor.

Figure 2 illustrates the baseline demographic characteristics of the participants included in the study. Two thirds of the study population were female. There was a statistically significant difference between baseline ages of male participants (Median: 39; IQR: 34 - 45) and female participants (Median: 35; IQR: 30 - 41) baseline age with males being older $(\mathrm{p}<0.01)$.

In the univariate analysis of sex as a risk factor, being male was a statistically significant risk factor (RR: 1.57; CI: 1.05 - 2.33; p: 0.03). Among the age groups, significant risk groups were participants aged 46 - 55 years (RR: 1.63; CI: 1.01 - 2.63; p: 0.045) and those above age 55 years (RR: 4.39; CI: $2.61-7.40$; p: < 0.01). Participants

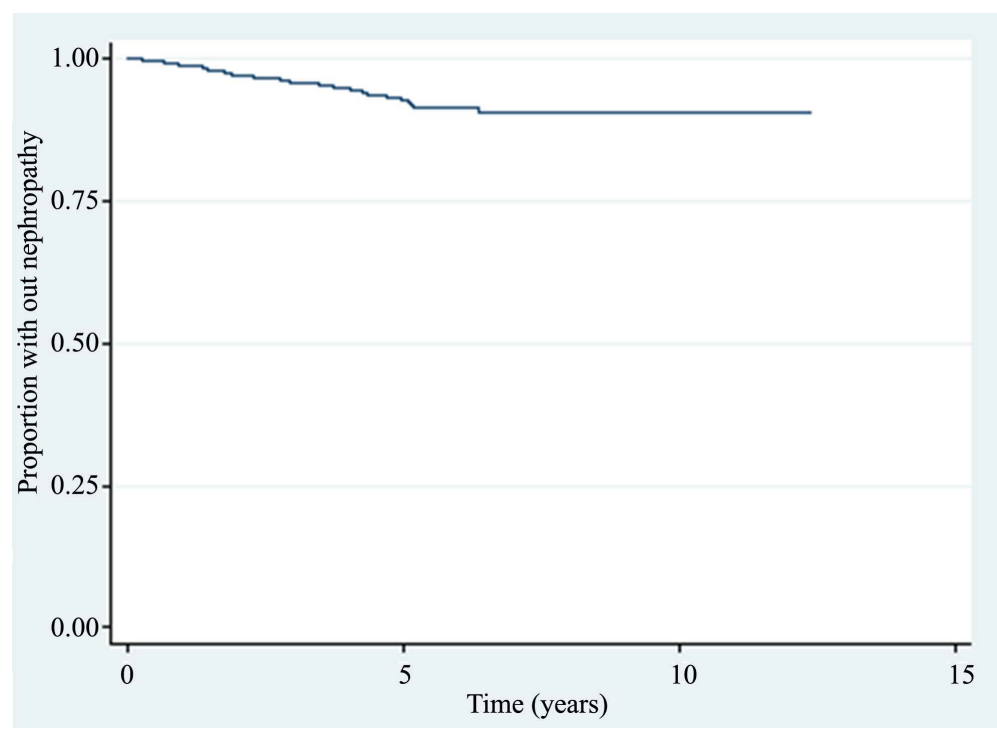

Figure 1. Kaplan-Meier survival estimate showing the development of nephropathy over time beginning at ART commencement. 


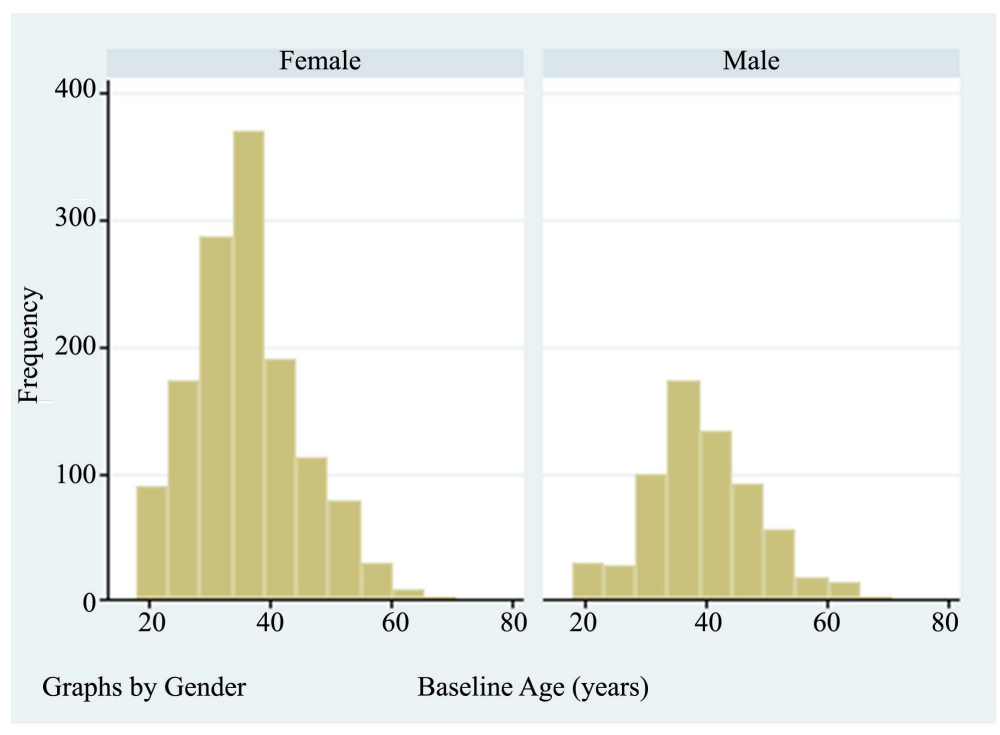

Figure 2. Baseline age distribution of female and male participants.

that developed nephropathy had a higher median baseline age (Median: 44; IQR: 37 - 56) than those that did not (Median: 40; IQR: 35 - 47) and this difference was statistically significant $(\mathrm{p}=0.01)$.

Baseline clinical characteristics and results of their univariate analysis summarised in Table 1. The majority of participants (58.1\%) presented to the clinic in early stages of disease i.e. WHO stage 1 and 2. Male patients presented later with more severe immunosuppression compared to female patients. A higher proportion of males (48.2\%) presented with WHO stage 3 or 4 defining conditions, compared to 38.9\% females. Baseline CD4+ cell counts were significantly lower for males than females ( $<0.01$ ), with $57.6 \%$ having a baseline CD4 count $\leq 200$ compared to $42.2 \%$ of females.

Tuberculosis was the most common opportunistic infection with 332 (16.7\%) participants having been diagnosed with pulmonary tuberculosis and 110 (5.5\%) extrapulmonary tuberculosis. Hypertensive patients constituted 11.6\% $(n=231 / 1986)$ of the cohort.

Baseline WHO stage 3, pulmonary tuberculosis, extrapulmonary tuberculosis, oesophageal candidiasis, HIV wasting syndrome, diabetes mellitus and hypertension were statistically significant risk factors. The median baseline CD4+ cell count was higher among patients without nephropathy (Median: 214; IQR: 113 - 334) than those with nephropathy (Median: 156; IQR: 83 - 322) but this difference was not statistically significant.

None of the participants who developed nephropathy had a history of pneumocystis jiroveci pneumonia (PCP).

The most commonly prescribed NSAIDs were Diclofenac and Ibuprofen. Ciprofloxacin was the most commonly prescribed fluoroquinolone with almost half the patients having received a prescription, and none of the participants that developed nephropathy having received norfloxacin or of loxacin. The commonly prescribed ACEI was captopril. One participant received enalapril while none received losartan. The majority of participants (96.5\%) received TDF containing ART regimens, while none received IDV. Treatment characteristics are summarised in Table 2.

In the univariate analysis of treatment risk factors summarised in Table 2, only exposure to indomethacin among the NSAIDs was a statistically significant risk factor. Exposure to any of the antibiotics or the antiviral acyclovir was not a statistically significant risk factor. Exposure to ACEI captopril was also a significant risk factor (RR: 4.35; CI: 2.06 - 9.18; p < 0.01). Exposure to any of the antiretrovirals was not a statistically significant risk factor.

Diabetes mellitus, pulmonary tuberculosis, HIV wasting syndrome and age greater than 46 years were the statistically significant risk factors in the Cox regression model (Breslow method for ties) for multivariate analysis shown in Table 3 . When the age groups above 45 years were disaggregated, the age group above 55 years had a higher hazard ratio (HR: 3.55, CI: $1.92-6.53, \mathrm{p}<0.01$ ).

1784 (90.0\%) participants were retained in the care at the end of the study. Participant outcomes are summa- 
Table 1. Clinical characteristics of HIV infected participants enrolled at Newlands Clinic between January 2007 and December 2013; and univariate analysis results. $\mathrm{N}=1986$.

\begin{tabular}{|c|c|c|c|c|c|c|}
\hline Characteristic & Total n (\%) & $\begin{array}{c}\text { Nephropathy } \\
\text { n (\%) }\end{array}$ & $\begin{array}{c}\text { No Nephropathy n } \\
\text { (\%) }\end{array}$ & $\mathbf{R R}$ & CI & p-Value \\
\hline \multicolumn{7}{|c|}{ Severity of Immunosuppression } \\
\hline \multicolumn{7}{|l|}{ Baseline WHO Stage } \\
\hline 1 & $633(32.3)$ & $18(19.6)$ & $615(33.0)$ & 0.51 & $0.31-0.84$ & 0.01 \\
\hline 2 & $505(25.8)$ & $20(21.7)$ & $485(26.0)$ & 0.8 & $0.49-1.29$ & 0.36 \\
\hline 3 & $638(32.6)$ & $42(45.7)$ & 596 (31.9) & 1.74 & $1.17-2.59$ & 0.01 \\
\hline 4 & $182(9.3)$ & $12(13.0)$ & $170(9.1)$ & 1.46 & $0.81-2.63$ & 0.2 \\
\hline $\begin{array}{l}\text { Baseline CD4 Count } \\
\text { (cells/ } / \mu \mathrm{L} \text { )-Median (IQR) }\end{array}$ & $\begin{array}{c}212 \\
(112-333)\end{array}$ & $210(162)$ & $243(174)$ & & & 0.04 \\
\hline \multicolumn{7}{|c|}{ Opportunistic Infections } \\
\hline Cryptococcal Meningitis & $34(1.7)$ & $3(3.2)$ & $31(1.6)$ & 1.91 & $0.64-5.74$ & 0.25 \\
\hline Pulmonary Tuberculosis & $332(16.7)$ & $34(36.6)$ & $298(15.7)$ & 2.87 & $1.91-4.30$ & $<0.01$ \\
\hline Extrapulmonary Tuberculosis & $110(5.5)$ & $10(10.8)$ & $100(5.3)$ & 2.05 & $1.10-3.85$ & 0.02 \\
\hline Oesophageal Candidiasis & $81(4.1)$ & $9(9.7)$ & $72(3.8)$ & 2.53 & $1.31-4.83$ & $<0.01$ \\
\hline \multicolumn{7}{|c|}{ Other AIDS Defining Conditions } \\
\hline Severe Weight Loss & $33(1.7)$ & $1(1.1)$ & $32(1.7)$ & 0.64 & $0.09-4.48$ & 0.65 \\
\hline HIV Wasting Syndrome & $58(2.9)$ & $9(9.7)$ & $49(2.6)$ & 3.56 & $1.89-6.73$ & $<0.01$ \\
\hline Kaposi Sarcoma & $15(0.8)$ & $1(1.1)$ & $14(0.7)$ & 1.43 & $0.21-9.59$ & 0.72 \\
\hline \multicolumn{7}{|c|}{ Comorbidities } \\
\hline Diabetes mellitus & $28(1.4)$ & $6(6.5)$ & $22(1.2)$ & 4.82 & $2.3-10.1$ & $<0.01$ \\
\hline Hypertension & $231(11.6)$ & $20(21.5)$ & $211(11.2)$ & 2.08 & $1.29-3.34$ & $<0.01$ \\
\hline
\end{tabular}

rised in Table 4. The proportion of participants deceased was higher among those that developed nephropathy $(17 / 93)$ than in those that did not $(60 / 1890)(\mathrm{p}<0.001)$.

\section{Discussion}

Our study demonstrated a low incidence rate of nephropathy (1.45/100 person-years) which was consistent with that found in other studies by Lucas et al. (CKD 12.5/1000 person-years among African American participants) and Mocroft et al. (1.05/100 person-years) [11] [22].

We identified diabetes mellitus, older age, a diagnosis history of tuberculosis and HIV wasting syndrome as significant independent risk factors for nephropathy. This is a confirmation of what has been shown previously in different populations. A diagnosis of pulmonary tuberculosis is a WHO stage 3 conditions, and that of HIV wasting syndrome is a WHO stage 4 condition. This suggests that the underlying cause is a longer interval of untreated HIV infection although the use of rifampicin in patients with tuberculosis is also a documented risk factor for nephropathy [40] [41].

The younger age of female participants compared to males might in part be explained by the national Prevention of Mother to Child Transmission (PMTCT) program which provides routine Provider Initiated HIV Testing and Counselling (PITC) to all pregnant women in Zimbabwe [18] [42]. Since the majority of pregnant women are in the 20 - 24 age group, this programme facilitates the enrolment of women into ART clinics at a younger age, and young mothers become beneficiaries of this facility [43]. As a result, male patients were not only older but also had lower CD4+ cell counts and a greater proportion of them had WHO stage 3 and 4 conditions than their female counterparts. 
Table 2. Medications characteristics of HIV infected participants enrolled at Newlands Clinic between January 2007 and December 2013; and univariate analysis results. $\mathrm{N}=1986$.

\begin{tabular}{|c|c|c|c|c|c|c|}
\hline Medications $^{\mathrm{a}}$ & $\begin{array}{l}\text { Total } \\
\text { n (\%) }\end{array}$ & Nephropathy n (\%) & $\begin{array}{c}\text { No } \\
\text { Nephropathyn (\%) }\end{array}$ & $\mathbf{R R}$ & CI & p-Value \\
\hline Any NSAIDs & $1406(70.8)$ & $63(67.7)$ & 1343 (70.9) & 0.87 & $0.57-1.32$ & 0.51 \\
\hline Aspirin & $20(1.0)$ & $2(2.2)$ & $18(1.0)$ & 2.16 & $0.57-8.17$ & 0.23 \\
\hline Diclofenac & $1294(65.2)$ & $58(62.4)$ & $1236(65.3)$ & 0.89 & $0.59-1.33$ & 0.56 \\
\hline Ibuprofen & $701(35.3)$ & $28(30.1)$ & $673(35.6)$ & 0.79 & $0.51-1.21$ & 0.28 \\
\hline Indomethacin & 244 (12.3) & $16(17.2)$ & $228(12.0)$ & 1.48 & $0.88-2.50$ & 0.14 \\
\hline \multicolumn{7}{|l|}{ Antibiotics } \\
\hline Rifampicin & $183(10.2)$ & $11(11.8)$ & $172(9.1)$ & 1.32 & $0.72-2.43$ & 0.37 \\
\hline Isoniazide & $184(9.2)$ & $11(11.8)$ & $173(9.1)$ & 1.31 & $0.71-2.41$ & 0.38 \\
\hline Any Fluoroquinolones & $814(41.0)$ & $45(48.4)$ & 769 (40.6) & 1.35 & $0.91-2.01$ & 0.14 \\
\hline Ciprofloxacin & $813(40.9)$ & $45(48.4)$ & $768(40.6)$ & 1.35 & $0.91-2.01$ & 0.13 \\
\hline \multicolumn{7}{|l|}{ Antivirals } \\
\hline Acyclovir & $561(28.2)$ & $32(34.4)$ & $529(28.0)$ & 1.33 & $0.88-2.02$ & 0.17 \\
\hline \multicolumn{7}{|l|}{ Anti-hypertensives } \\
\hline ACEI & $49(2.5)$ & $7(7.5)$ & $42(2.2)$ & 3.22 & $1.57-6.59$ & $<0.01$ \\
\hline Captopril & $31(1.6)$ & $6(6.5)$ & $25(1.3)$ & 4.35 & $2.06-9.18$ & $<0.01$ \\
\hline \multicolumn{7}{|l|}{ Antiretrovirals } \\
\hline Tenofovir & $1862(93.8)$ & $56(60.2)$ & $1806(95.4)$ & 0.1 & $0.07-0.15$ & $<0.01$ \\
\hline Abacavir & $116(5.8)$ & $6(6.5)$ & $110(5.8)$ & 1.11 & $0.50-2.50$ & 0.8 \\
\hline Atazanavir & $104(5.2)$ & $1(1.1)$ & $103(5.4)$ & 0.2 & $0.03-1.40$ & 0.07 \\
\hline Lopinavir/r & 196 (9.9) & $7(7.5)$ & $189(10.0)$ & 0.74 & $0.35-1.58$ & 0.44 \\
\hline
\end{tabular}

${ }^{\mathrm{a}}$ Some patients received more than one medication in each of the classes at different times. Records represent patients that received at least one prescription of each medication.

Table 3. Multivariate analysis for independent risk factors.

\begin{tabular}{|c|c|c|c|}
\hline Risk Factor & HR & CI & p-Value \\
\hline Male & 1.42 & $0.93-2.17$ & 0.107 \\
\hline Diabetes mellitus & 3.17 & $1.28-7.87$ & 0.013 \\
\hline Hypertension & 1.32 & $0.75-2.34$ & 0.338 \\
\hline Pulmonary Tuberculosis & 1.84 & $1.14-2.99$ & 0.013 \\
\hline Extrapulmonary Tuberculosis & 1.35 & $0.61-2.98$ & 0.461 \\
\hline HIV Wasting Syndrome & 2.55 & $1.19-5.42$ & 0.015 \\
\hline Captopril Prescription & 1.58 & $0.63-3.96$ & 0.33 \\
\hline Age $>46$ (years) & 2.00 & $1.26-3.18$ & 0.003 \\
\hline WHO stage 3 or 4 & 1.16 & $0.73-1.85$ & 0.525 \\
\hline
\end{tabular}


Table 4. Participant outcomes.

\begin{tabular}{cccc}
\hline Patient Outcome & $\begin{array}{c}\text { Nephropathy } \\
\text { n (\%) }\end{array}$ & $\begin{array}{c}\text { No Nephropathy } \\
\text { n (\%) }\end{array}$ & $\begin{array}{c}\text { Total } \\
\text { n (\%) }\end{array}$ \\
\hline Active & $72(77.4)$ & $1712(90.6)$ & $1784(90.0)$ \\
Deceased & $17(18.3)$ & $60(3.2)$ & $77(3.9)$ \\
Lost to Follow Up & $1(1.1)$ & $41(2.2)$ & $42(2.1)$ \\
Stopped ART & $0(0.0)$ & $3(0.2)$ & $3(0.2)$ \\
Transferred Out & $3(3.2)$ & $74(3.9)$ & $77(3.9)$ \\
Total & $93(100)$ & $1890(100)$ & $1983(100)^{\mathrm{b}}$ \\
\hline
\end{tabular}

${ }^{\mathrm{b}}$ Three patients did not have a patient state assigned.

The limitations of this study primarily arise from the retrospective design. More precise measurements like urine and plasma phosphate, $\beta 2$ microglobulin and microalbumin could not be used as these laboratory tests were not available during the time of the study. Acute kidney injury (AKI) could not be assessed because secondary data was used with creatinine clearance measurements having been done three to six months apart. The definition of nephropathy used in this study is neither exhaustive of all forms of nephropathy nor accurate. It only gives an indication of the burden. Kidney biopsies would have been more informative especially for HIVAN.

Due to the standard practice at the clinic where patients were screened for kidney function prior to initiation on TDF containing ART regimens, there is a channelling bias inherent in the cohort as far as the analysis of TDF as a risk factor because patients with compromised renal function were not initiated on the antiretroviral agent. There is also the likely misclassification bias due to the measurements used to define nephropathy as far as TDF toxicity is concerned. It would have been more appropriate to use biomarkers that directly measure tubular toxicity in addition to creatinine clearance.

None of the medications that were assessed were statistically significant as independent risk factors for nephropathy.

The study period spans across eras where different regimens were recommended as first line in Zimbabwe and used at Newlands Clinic. In the earlier part of 2007 to 2011, the alternative first line was predominantly used at the clinic which consisted of zidovudine/lamivudine/nevirapine [44]. The 2010 guidelines for antiretroviral therapy in Zimbabwe then introduced a different preferred first line regimen of tenofovir/lamivudine/nevirapine [18].

Although there are quality checks to ensure the data quality integrity, the data that was analysed was collected for operational purposes and not for research purposes. Clinicians collecting the data were not operating using standardised methods as in a research context, but the information collected was done as part of clinical care.

\section{Conclusion}

The incidence of nephropathy was low in this cohort. The traditional risk factors for renal disease including older age and diabetes mellitus emerged as significant independent risk factors. HIV wasting syndrome and history of pulmonary tuberculosis were also independent risk factors suggesting that advanced disease is probably a risk factor for the development of nephropathy. In order to detect, and prevent the development of nephropathy in HIV infected patients, it is important that ART should be started early, and ART care services should be complimented with proper diabetic care. Patients that develop pulmonary tuberculosis, HIV wasting syndrome or are initiated on ART above the age of 45 years should have regular assessments of renal function.

\section{Acknowledgements}

We acknowledge the input of Swiss Aids Care International (SACI), the Newlands Clinic Research Team, University of Zimbabwe College of Health Sciences (UZ-CHS), Biomedical Research and Training Institute (BRTI), and the International Clinical, Operational, and Health Services Research Training Award (ICOHRTA) for AIDS and Tuberculosis towards this work. 


\section{References}

[1] Campbell, G.L.J., Ibrahim, F., Fisher, M., Holt, S.G., Hendry, B.M. and Post, F.A. (2009) Spectrum of Chronic Kidney Disease in HIV-Infected Patients. HIV Medicine, 10, 329-336. http://dx.doi.org/10.1111/j.1468-1293.2008.00691.X

[2] Gupta, S.K., Eustace, J.A., Winston, J.A., Boydstun, I.I., Ahuja, T.S., Rodriguez, R.A., Tashima, K.T., Roland, M., Franceschini, N., Palella, F.J., Lennox, J.L., Klotman, P.E., Nachman, S.A., Hall, S.D. and Szczech, L.A. (2005) Guidelines for the Management of Chronic Kidney Disease in HIV-Infected Patients: Recommendations of the HIV Medicine Association of the Infectious Diseases Society of America. Clinical Infectious Diseases, 40, 1559-1585. http://dx.doi.org/10.1086/430257

[3] Bruggeman, L.A., Ross, M.D., Tanji, N., Cara, A., Dikman, S., Gordon, R.E., Burns, G.C., D’Agati, V.D., Winston, J.A., Klotman, M.E. and Klotman, P.E. (2000) Renal Epithelium Is a Previously Unrecognized Site of HIV-1 Infection. Journal of the American Society of Nephrology, 11, 2079-2087.

[4] Marras, D., Bruggeman, L.A., Gao, F., Tanji, N., Mansukhani, M.M., Cara, A., Ross, M.D., Gusella, G.L., Benson, G., D’Agati, V.D., Hahn, B.H., Klotman, M.E. and Klotman, P.E. (2002) Replication and Compartmentalization of HIV-1 in Kidney Epithelium of Patients with HIV-Associated Nephropathy. Nature Medicine, 8, 522-526. http://dx.doi.org/10.1038/nm0502-522

[5] Barisoni, L., Bruggeman, L.A., Mundel, P., D’Agati, V.D. and Klotman, P.E. (2000) HIV-1 Induces Renal Epithelial Dedifferentiation in a Transgenic Model of HIV-Associated Nephropathy. Kidney International, 58, 173-181. http://dx.doi.org/10.1046/j.1523-1755.2000.00152.x

[6] Gerntholtz, T.E., Goetsch, S.J.W. and Katz, I. (2006) HIV-Related Nephropathy: A South African Perspective. Kidney International, 69, 1885-1891. http://dx.doi.org/10.1038/sj.ki.5000351

[7] Wyatt, C.M. and Klotman, P.E. (2007) HIV-1 and HIV-Associated Nephropathy 25 Years Later. Clinical Journal of the American Society of Nephrology, 2, S20-S24.

[8] Genovese, G., Friedman, D.J., Ross, M.D., Lecordier, L., Uzureau, P., Freedman, B.I., Bowden, D.W., Langefeld, C.D., Oleksyk, T.K., Uscinski Knob, A.L., Bernhardy, A.J., Hicks, P.J., Nelson, G.W., Vanhollebeke, B., Winkler, C.A., Kopp, J.B., Pays, E. and Pollak, M.R. (2010) Association of Trypanolytic ApoL1 Variants with Kidney Disease in African Americans. Science, 329, 841-845. http://dx.doi.org/10.1126/science.1193032

[9] Han, T.M., Naicker, S., Ramdial, P.K. and Assounga, A.G. (2006) A Cross-Sectional Study of HIV-Seropositive Patients with Varying Degrees of Proteinuria in South Africa. Kidney International, 69, 2243-2250. http://dx.doi.org/10.1038/sj.ki.5000339

[10] Wyatt, C.M. (2008) HIV and the Kidney: A Spotlight on Racial Disparities. Journal of Infectious Diseases, 197, 14901492. http://dx.doi.org/10.1086/587995

[11] Lucas, G.M., Lau, B., Atta, M.G., Fine, D.M., Keruly, J. and Moore, R.D. (2008) Chronic Kidney Disease Incidence, and Progression to End-Stage Renal Disease, in HIV-Infected Individuals: A Tale of Two Races. The Journal of Infectious Diseases, 197, 1548-1557. http://dx.doi.org/10.1086/587994

[12] Wyatt, C.M. and Klotman, P.E. (2007) HIV-1 and HIV-Associated Nephropathy 25 Years Later. Clinical Journal of the American Society of Nephrology, 2, S20-S24. http://dx.doi.org/10.2215/CJN.03561006

[13] Schwartz, E.J., Szczech, L.A., Ross, M.J., Klotman, M.E., Winston, J.A. and Klotman, P.E. (2005) Highly Active Antiretroviral Therapy and the Epidemic of HIV+ End-Stage Renal Disease. Journal of the American Society of Nephrology, 16, 2412-2420. http://dx.doi.org/10.1681/ASN.2005040340

[14] Bigé, N., Lanternier, F., Viard, J.-P., Kamgang, P., Daugas, E., Elie, C., Jidar, K., Walker-Combrouze, F., Peraldi, M.-N., Isnard-Bagnis, C., Servais, A., Lortholary, O., Noël, L.-H. and Bollée, G. (2012) Presentation of HIV-Associated Nephropathy and Outcome in HAART-Treated Patients. Nephrology Dialysis Transplantation, 27, 1114-1121. http://dx.doi.org/10.1093/ndt/gfr376

[15] Gallant, J.E., Staszewski, S., Pozniak, A.L., De Jesus, E., Suleiman, J.M.A.H., Miller, M.D., Coakley, D.F., Lu, B., Toole, J.J. and Cheng, A.K. (2004) Efficacy and Safety of Tenofovir DF vs. Stavudine in Combination Therapy in Antiretroviral-Naive Patients: A 3-Year Randomized Trial. JAMA, 292, 191-201. http://dx.doi.org/10.1001/jama.292.2.191

[16] Gallant, J.E., DeJesus, E., Arribas, J.R., Pozniak, A.L., Gazzard, B., Campo, R.E., Lu, B., McColl, D., Chuck, S., Enejosa, J., Toole, J.J. and Cheng, A.K. (2006) Tenofovir DF, Emtricitabine, and Efavirenz vs. Zidovudine, Lamivudine, and Efavirenz for HIV. New England Journal of Medicine, 354, 251-260. http://dx.doi.org/10.1056/NEJMoa051871

[17] Izzedine, H., Hulot, J.S., Vittecoq, D., Gallant, J.E., Staszewski, S., Launay-Vacher, V., Cheng, A. and Deray, G. (2005) Long-Term Renal Safety of Tenofovir Disoproxil Fumarate in Antiretroviral-Naive HIV-1-Infected Patients. Data from a Double-Blind Randomized Active-Controlled Multicentre Study. Nephrology Dialysis Transplantation, 20, 743-746. http://dx.doi.org/10.1093/ndt/gfh658

[18] Zimbabwe Advisory, National Drug and Therapeutics Policy (NDTPAC), Committee and the AIDS and TB Unit, 
Ministry of Health and Child Welfare (2010) Guidelines for Antiretroviral Therapy in Zimbabwe.

[19] Yeh, K.C., Deutsch, P.J., Haddix, H., Hesney, M., Hoagland, V., Ju, W.D., Justice, S.J., Osborne, B., Sterrett, A.T., Stone, J.A., Woolf, E. and Waldman, S. (1998) Single-Dose Pharmacokinetics of Indinavir and the Effect of Food. Antimicrobial Agents and Chemotherapy, 42, 332-338.

[20] Fernandez-Fernandez, B., Montoya-Ferrer, A., Sanz, A.B., Sanchez-Niño, M.D., Izquierdo, M.C., Poveda, J., SainzPrestel, V., Ortiz-Martin, N., Parra-Rodriguez, A., Selgas, R., Ruiz-Ortega, M., Egido, J. and Ortiz, A. (2011) Tenofovir Nephrotoxicity: 2011 Update. AIDS Research and Treatment, 2011, Article ID: 354908. http://dx.doi.org/10.1155/2011/354908

[21] Kalyesubula, R. and Perazella, M.A. (2011) Nephrotoxicity of HAART. AIDS Research and Treatment, 2011, Article ID: 562790 .

[22] Mocroft, A., Kirk, O., Reiss, P., De Wit, S., Sedlacek, D., Beniowski, M., Gatell, J., Phillips, A.N., Ledergerber, B. and Lundgren, J.D. (2010) Estimated Glomerular Filtration Rate, Chronic Kidney Disease and Antiretroviral Drug Use in HIV-Positive Patients. AIDS, 24, 1667-1678. http://dx.doi.org/10.1097/QAD.0b013e328339fe53

[23] Mocroft, A., Kirk, O., Gatell, J., Reiss, P., Gargalianos, P., Zilmer, K., Beniowski, M., Viard, J.-P., Staszewski, S. and Lundgren, J.D. (2007) Chronic Renal Failure among HIV-1-Infected Patients. AIDS, 21, 1119-1127. http://dx.doi.org/10.1097/QAD.0b013e3280f774ee

[24] Sax, P.E., Gallant, J.E. and Klotman, P.E. (2007) Renal safety of Tenofovir Disoproxil Fumarate. The AIDS Reader, 17, 90-92, 99-104, C3.

[25] Cooper, R.D., Wiebe, N., Smith, N., Keiser, P., Naicker, S. and Tonelli, M. (2010) Systematic Review and Meta-Analysis: Renal Safety of Tenofovir Disoproxil Fumarate in HIV-Infected Patients. Clinical Infectious Diseases, 51, 496-505. http://dx.doi.org/10.1086/655681

[26] Hall, A.M., Hendry, B.M., Nitsch, D. and Connolly, J.O. (2011) Tenofovir-Associated Kidney Toxicity in HIV-Infected Patients. American Journal of Kidney Diseases, 57, 773-780.

[27] Longenecker, J.C., Coresh, J., Klag, M.J., Levye, A.S., Martin, A.A., Fink, N.E. and Powe, N.R. (2000) Validation of Comorbid Conditions on the End-Stage Renal Disease Medical Evidence Report: The CHOICE Study. Journal of the American Society of Nephrology, 11, 520-529.

[28] Foster, M.C., Rawlings, A.M., Marrett, E., Neff, D., Willis, K., Inker, L.A., Coresh, J. and Selvin, E. (2013) Cardiovascular Risk Factor Burden, Treatment, and Control among Adults with Chronic Kidney Disease in the United States. American Heart Journal, 166, 150-156. http://dx.doi.org/10.1016/j.ahj.2013.03.016

[29] Parikh, N.I., Hwang, S.-J., Larson, M.G., Meigs, J.B., Levy, D. and Fox, C.S. (2006) Cardiovascular Disease Risk Factors in Chronic Kidney Disease: Overall Burden and Rates of Treatment and Control. Archives of Internal Medicine, 166, 1884-1891. http://dx.doi.org/10.1001/archinte.166.17.1884

[30] Roberts, M.A., Hare, D.L., Ratnaike, S. and Ierino, F.L. (2006) Cardiovascular Biomarkers in CKD: Pathophysiology and Implications for Clinical Management of Cardiac Disease. American Journal of Kidney Diseases, 48, 341-360. http://dx.doi.org/10.1053/j.ajkd.2006.06.005

[31] Ando, M., Yanagisawa, N., Ajisawa, A., Tsuchiya, K. and Nitta, K. (2011) Kidney Tubular Damage in the Absence of Glomerular Defects in HIV-Infected Patients on Highly Active Antiretroviral Therapy. Nephrology Dialysis Transplantation, 26, 3224-3229. http://dx.doi.org/10.1093/ndt/gfr020

[32] Ando, M., Tsuchiya, K. and Nitta, K. (2012) How to Manage HIV-Infected Patients with Chronic Kidney Disease in the HAART Era. Clinical and Experimental Nephrology, 16, 363-372. http://dx.doi.org/10.1007/s10157-012-0585-7

[33] Goulet, J.L., Fultz, S.L., Rimland, D., Butt, A., Gibert, C., Rodriguez-Barradas, M., Bryant, K. and Justice, A.C. (2007) Aging and Infectious Diseases: Do Patterns of Comorbidity Vary by HIV Status, Age, and HIV Severity? Clinical Infectious Diseases, 45, 1593-1601. http://dx.doi.org/10.1086/523577

[34] Wikman, P., Safont, P., Del Palacio, M., Moreno, A., Moreno, S. and Casado, J.L. (2013) The Significance of Antiretroviral-Associated Acute Kidney Injury in a Cohort of Ambulatory Human Immunodeficiency Virus-Infected Patients. Nephrology Dialysis Transplantation, 28, 2073-2081. http://dx.doi.org/10.1093/ndt/gft210

[35] Griffin, L. and Standridge, J.B. (2012) A Systematic Review of Randomized Controlled Trials Examining the Nephroprotective Properties of Antihypertensive Medications. Current Hypertension Reviews, 8, 196-226. http://dx.doi.org/10.2174/157340212803530394

[36] Gupta, S.K., Eustace, J.A., Winston, J.A., Boydstun, I.I., Ahuja, T.S., Rodriguez, R.A., Tashima, K.T., Roland, M., Franceschini, N., Palella, F.J., Lennox, J.L., Klotman, P.E., Nachman, S.A., Hall, S.D. and Szczech, L.A. (2005) Guidelines for the Management of Chronic Kidney Disease in HIV-Infected Patients: Recommendations of the HIV Medicine Association of the Infectious Diseases Society of America. Clinical Infectious Diseases, 40, 1559-1585. http://dx.doi.org/10.1086/430257

[37] Gardner, L.I., Holmberg, S.D., Williamson, J.M., Szczech, L.A., Carpenter, C.C.J., Rompalo, A.M., Schuman, P., 
Klein, R.S. and Al, G.E.T. (2003) Development of Proteinuria or Elevated Serum Creatinine and Mortality in HIV-Infected Women. Journal of Acquired Immune Deficiency Syndromes, 32, 203-209.

[38] Amin, S., Clarke, S.E. and Halai, M. (2014) British National Formulary. March-Se. BMJ Group and the Royal Pharmaceutical Society of Great Britain.

[39] Aberg, J.A., Gallant, J.E., Ghanem, K.G., Emmanuel, P., Zingman, B.S. and Horberg, M.A., Infectious Diseases Society of America (2014) Primary Care Guidelines for the Management of Persons Infected with HIV: 2013 Update by the HIV Medicine Association of the Infectious Diseases Society of America. Clinical Infectious Diseases, 58, e1-e34. http://dx.doi.org/10.1093/cid/cit665

[40] Kalyesubula, R. and Perazella, M.A. (2011) Nephrotoxicity of HAART. AIDS Research and Treatment, 2011, Article ID: 562790. http://dx.doi.org/10.1155/2011/562790

[41] Winston, J.A., Klotman, M.E. and Klotman, P.E. (1999) HIV-Associated Nephropathy Is a Late, Not Early, Manifestation of HIV-1 Infection. Kidney International, 55, 1036-1040. http://dx.doi.org/10.1046/j.1523-1755.1999.0550031036.x

[42] Chandisarewa, W., Stranix-Chibanda, L., Chirapa, E., Miller, A., Simoyi, M., Mahomva, A., Maldonado, Y. and Shetty, A.K. (2007) Routine Offer of Antenatal HIV Testing ('Opt-Out' Approach) to Prevent Mother-to-Child Transmission of HIV in Urban Zimbabwe. Bulletin of the World Health Organization, 85, 843-850. http://dx.doi.org/10.2471/BLT.06.035188

[43] Zimbabwe National Statistics Agency (ZIMSTAT) and ICF International (2012) Zimbabwe Demographic and Health Survey 2010-11.

[44] Ministry of Health \& Child Welfare-Zimbabwe (2004) Prevention of Opportunistic Infections—Training Course for Health Care Providers, February 2004. 